Analytical Methods

\title{
Winery by-products: Extraction optimization, phenolic composition and cytotoxic evaluation to act as a new source of scavenging of reactive oxygen species
}

\author{
Priscilla Siqueira Melo ${ }^{a}$, Adna Prado Massarioli ${ }^{a}$, Carina Denny ${ }^{b}$, Luciana Ferracini dos Santos ${ }^{c}$, \\ Marcelo Franchin ${ }^{\mathrm{b}}$, Giuliano Elias Pereira ${ }^{\mathrm{d}}$, Thais Maria Ferreira de Souza Vieira ${ }^{\mathrm{a}}$, Pedro Luiz Rosalen ${ }^{\mathrm{b}}$, \\ Severino Matias de Alencar ${ }^{\text {a,* }}$

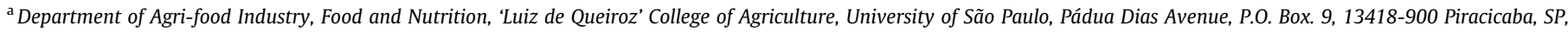 \\ Brazil \\ ${ }^{\mathrm{b}}$ Piracicaba Dental School, Department of Physiological Sciences, University of Campinas, 901, Limeira Avenue, 13414-903 Piracicaba, SP, Brazil \\ ${ }^{\mathrm{c}}$ Herminio Ometto University Center, 500, Dr. Maximiliano Baruto, 13607-339 Araras, SP, Brazil \\ d Brazilian Agricultural Research Corporation - Embrapa Grape E Wine/Tropical Semi-arid, BR 428, Km 152, P.O. Box 23, 56302-970 Petrolina, PE, Brazil
}

\section{A R T I C L E I N F O}

\section{Article history:}

Received 20 October 2014

Received in revised form 14 February 2015

Accepted 17 February 2015

Available online 24 February 2015

Chemical compounds studied in this article: Catechin (PubChem CID: 73160)

Procyanidin B1 (PubChem CID: 11250133)

Epicatechin (PubChem CID: 72276)

Procyanidin B2 (PubChem CID: 122738)

Gallic acid (PubChem CID: 370 )

Malvidin-3-glucoside (PubChem CID:

443652)

\section{Keywords:}

Winery by-products

Anthocyanins

Response surface methodology (RSM)

Reactive oxygen species (ROS)

Cytotoxicity (MTT)

\begin{abstract}
A B S T R A C T
Nearly 20 million tons of winery by-products, with many biological activities, are discarded each year in the world. The extraction of bioactive compounds from Chenin Blanc, Petit Verdot, and Syrah grape byproducts, produced in the semi-arid region in Brazil, was optimized by a Central Composite Rotatable Design. The phenolic compounds profile, antioxidant capacity against synthetic free radicals (DPPH and ABTS), reactive oxygen species (ROS; peroxyl radical, superoxide radical, hypochlorous acid), cytotoxicity assay (MTT) and quantification of TNF- $\alpha$ production in RAW 264.7 cells were conducted. Gallic acid, syringic acid, procyanidins B1 and B2, catechin, epicatechin, epicatechin gallate, quercetin 3- $\beta-D-$ glucoside, delfinidin 3-glucoside, peonidin 3-O-glucoside, and malvidin 3-glucoside were the main phenolic compounds identified. In general, rachis showed higher antioxidant capacity than pomace extract, especially for Chenin Blanc. All extracts showed low cytotoxicity against RAW 264.7 cells and Petit Verdot pomace suppressed TNF- $\alpha$ liberation in vitro. Therefore, these winery by-products can be considered good sources of bioactive compounds, with great potential for application in the food and pharmaceutical industries.
\end{abstract}

(c) 2015 Elsevier Ltd. All rights reserved.

\section{Introduction}

The world production of grapes and wine in 2012 was 67 million tons (FAO, 2014) and 252 million hectoliters (OIV, 2013), respectively. The vitiviniculture sector generates by-products, such as pomace (skin and seeds), rachis, and lees, equivalent to $30 \%$ of the total quantity of vinified grapes (Makris, Boskou, \& Andrikopoulos, 2007).

Supposing that the total grape crop production in 2012 had been processed, approximately 20 million tons of by-products

\footnotetext{
* Corresponding author. Tel.: +55 19 34294150; fax: +55 1934294288.

E-mail address: smalencar@usp.br (S.M.d. Alencar).
}

would have been generated, most of them discarded without any type of treatment, causing great environmental impact. Some studies have already demonstrated that these by-products can be sources of natural antioxidants, especially because they contain phenolic compounds (Melo et al., 2011).

As sources of natural antioxidants, these materials could be reused as additive substitutes or new ingredients in the food and/or pharmaceutical industries (Denny et al., 2014; Makris et al., 2007). Therefore, scientific foundation for the understanding of efficient methods of extraction, antioxidant activity in different reaction systems, and cytotoxicity assays are important for starting the reuse of these agro-industrial by-products in a large scale. Moreover, giving them a new destination could contribute to 
decrease the amount of organic material discarded in the environment, as well as increase the food utilization rate.

The winery by-products used in the present study were obtained from the French grape varieties Chenin Blanc, Petit Verdot, and Syrah. These grape varieties were cultivated and vinified in an important Brazilian vitiviniculture cluster, located in the municipality of Petrolina, in the São Francisco river valley, in the state of Pernambuco, Brazil, where the crop management practices are differentiated, since it is a semi-arid region (Pereira et al., 2011).

Therefore, this study aimed to assess the antioxidant potential of optimized extracts of winery by-products, which was measured using the scavenging capacity of synthetic free radicals and reactive oxygen species (ROS), as well as the characterization of their bioactive phenolic compounds, cytotoxicity, and TNF- $\alpha$ release in RAW 264.7 cells. To the best of our knowledge, this is the first time that the antioxidant potential of by-products from these three European grape varieties, acclimated to a strictly semi-arid region, are evaluated.

\section{Materials and methods}

\subsection{Winery by-products}

The winery by-products employed in this study, namely Chenin Blanc, Petit Verdot, and Syrah grape pomaces and rachis, were kindly provided by Embrapa Grape \& Wine/Tropical Semi-Arid (Petrolina, PE, Brazil), frozen, lyophilized, grounded, and stored at $-18^{\circ} \mathrm{C}$ until the extraction assays.

\subsection{Chemicals}

The following chemicals were used in this study: Folin-Ciocalteau reagent (Dinâmica Química Contemporânea, Diadema, SP, Brazil); sodium carbonate, potassium chloride, ethanol (Synth, Diadema, SP, Brazil); monobasic and dibasic potassium phosphate, the standards ( \pm )-6-hydroxy-2,5,7,8-tetramethylchromane-2-carboxylic acid (Trolox), gallic acid, syringic acid, procyanidins B1 and B2, catechin, epicatechin, quercetin 3- $\beta$-D-glucoside, delphinidin 3-O- $\beta$-D-glucoside, peonidin-3-O-glucoside, and malvidin-3-O-glucoside, and the reagents 1,1-diphenyl-2-pycrylhydrazyl (DPPH'), 2,2'-azino-bis (3-ethylbenzothiazoline-6-sulfonic acid) diammonium salt (ABTS), potassium peroxydisulfate, fluorescein sodium salt, 2,2'-azobis(2-methylpropionamidine) dihydrochloride $(\mathrm{AAPH}), \beta$-nicotinamide adenine dinucleotide (NADH), phenazine methosulfate (PMS), nitrotetrazolium blue chloride (NBT), sodium hypochlorite solution $(\mathrm{NaOCl})$, rhodamine 123 , sodium acetate trihydrate, 3-(4,5-dimethylthiazol-2-yl)-2,5-diphenyltetrazolium bromide (MTT) and Escherichia coli LPS were purchased from Sigma-Aldrich (St. Louis, MO, USA); acetonitrile and methanol were purchased from J.T. Baker (Phillipsburg, NJ, USA); formic acid was purchased from Tedia (Fairfield, OH, USA); fetal bovine serum (FBS), antibiotics (streptomycin/penicillin), and Dulbecco's modified Eagle medium (DMEM) were purchased from Vitrocell Embriolife (Campinas, SP, Brazil); water was obtained from a Millipore Milli-Q System (Millipore SAS, Molsheim, France).

\subsection{By-product extraction and optimization of experimental design using response surface methodology (RSM)}

In order to increase the extractability of bioactive compounds, a Central Composite Rotatable Design (CCRD) of two factors and five levels was applied to investigate the Trolox equivalent antioxidant capacity (TEAC). The explanatory variables were ethanol percent- age in water $(\% \mathrm{v} / \mathrm{v})$ and temperature $\left({ }^{\circ} \mathrm{C}\right)$. The experimental design with the range and center points is shown in Table 1.

By-product samples were weighted $(0.5 \mathrm{~g})$ and aliquots of $5 \mathrm{~mL}$ of the solvent in the established ethanol proportions were added to them. These mixtures remained for $20 \mathrm{~min}$ in a heated bath, at the temperatures provided by the experimental design (Table 1 ) and then sonicated (UltraCleaner 1400A, Unique, Indaiatuba, SP, Brazil) for $15 \mathrm{~min}$ at room temperature. After that, the extracts were centrifuged (Eppendorf 5810R, Eppendorf AG, Hamburg, Germany) at $5000 \times \mathrm{g}$ for $15 \mathrm{~min}$. The supernatant was filtered and analyzed for antioxidant activity. All the extractions were carried out in triplicate.

The effects of the independent variables were analyzed and mathematical models were adjusted, including linear, quadratic, and interactions of terms, represented by the following equation:

$Y=b_{0}+b_{1} X+b_{2} Z+b_{11} X^{2}+b_{22} Z^{2}+b_{12} X Z$

where $Y$ is the dependent variable (antioxidant activity), $b$ values are the constant coefficients, $X$ and $Z$ are coded values to the independent variables ethanol proportion and temperature, respectively, $b_{1} X$ and $b_{2} Z$ are the linear terms and represent the main effects, $b_{11} X^{2}$ and $b_{22} Z^{2}$ are the quadratic terms, and $b_{12} X Z$ refers to two effects of factor interaction (Hoffmann-Ribani \& Rodriguez-Amaya, 2008).

The quality of fit of the polynomial models was evaluated regarding the coefficient of determination $\left(R^{2}\right)$ and $F$-test. The lack of fit $F$-value $(p<0.05)$ was obtained by analysis of variance (ANOVA) and used to verify variable significance and model adequacy. The response surfaces were generated for each winery by-product. To define the best conditions for each material, after the generation of response surface graphs, the optimized intervals were identified, the samples with similar profile were grouped, and the conditions were selected.

\subsection{Determination of phenolic compounds}

\subsubsection{Total phenolic and monomeric anthocyanin pigment contents}

The analysis of total phenolic compounds was performed according to the spectrophotometric method of Folin-Ciocalteau described by Al-Duais, Müller, Böhm, and Jetschke (2009) with some modifications. Aliquots of $20 \mu \mathrm{L}$ of the standard solution (gallic acid) or the winery by-product extracts and $100 \mu \mathrm{L}$ of the FolinCiocalteau solution at the concentration of $10 \%$ in water were pipetted into each microplate well and, after $5 \mathrm{~min}$, aliquots of $75 \mu \mathrm{L}$ of $7.5 \%$ sodium carbonate aqueous solution were added to each well. The control was prepared by replacing the sample with distilled water. After 40 min of reaction, the absorbance was measured at $740 \mathrm{~nm}$ in a microplate reader (Molecular Devices, LLC, Sunnyvale, CA, USA). The calibration curve was plotted using gallic acid as standard at concentrations ranging from 20 to $120 \mu \mathrm{g} / \mathrm{mL}$.

Total monomeric anthocyanin pigment content was determined by the $\mathrm{pH}$ differential method, according to Lee, Durst, and Wrolstad (2005). The optimized by-product extracts were diluted in $0.025 \mathrm{M}$ potassium chloride solution ( $\mathrm{pH} 1.0$ ) and $0.4 \mathrm{M}$ sodium acetate buffer ( $\mathrm{pH} 4.5)$. The mixtures were incubated for $20 \mathrm{~min}$ in the dark and absorbance readings were made at 520 and $700 \mathrm{~nm}$ against the buffer and acid solution as blanks. The readings were converted to total mg of malvidin 3-glucoside (molecular weight $494 \mathrm{~g} / \mathrm{mol}$; molar absorptivity 36,400) and the results expressed as $\mathrm{mg}$ of malvidin equivalent per $\mathrm{g}$ of lyophilized winery by-product, using the following equation:

$\mathrm{TMA}=(A \times \mathrm{MW} \times \mathrm{DF} \times 1000) /(\varepsilon \times 1)$

where TMA is the total monomeric anthocyanin pigment content, $A$ is the absorbance differential $\left[\left(A_{520}-A_{700}\right)_{\mathrm{pH} 1}-\left(A_{520}-A_{700}\right)_{\mathrm{pH} 4.5}\right]$, 
Table 1

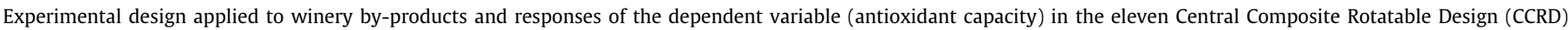
assays for each type of winery by-product assessed.

\begin{tabular}{|c|c|c|c|c|c|c|c|c|c|c|}
\hline \multirow[t]{3}{*}{ Run } & \multicolumn{4}{|c|}{ Independent variables } & \multicolumn{6}{|c|}{ Dependent variable: antioxidant capacity $(\mathrm{TEAC})^{\mathrm{a}}$} \\
\hline & \multicolumn{2}{|l|}{ Coded value } & \multicolumn{2}{|l|}{ Real value } & \multicolumn{2}{|c|}{ Chenin Blanc } & \multicolumn{2}{|c|}{ Petit Verdot } & \multicolumn{2}{|l|}{ Syrah } \\
\hline & Ethanol (\%) & Temp. $\left({ }^{\circ} \mathrm{C}\right)$ & Ethanol (\%) & Temp. $\left({ }^{\circ} \mathrm{C}\right)$ & Rachis & Pomace & Rachis & Pomace & Rachis & Pomace \\
\hline 1 & -1 & -1 & 15 & 36 & 966 & 128 & 370 & 295 & 372 & 121 \\
\hline 2 & 1 & -1 & 85 & 36 & 1058 & 162 & 268 & 555 & 533 & 194 \\
\hline 3 & -1 & 1 & 15 & 89 & 1119 & 167 & 562 & 380 & 375 & 242 \\
\hline 4 & 1 & 1 & 85 & 89 & 1443 & 211 & 357 & 468 & 542 & 353 \\
\hline 5 & 0 & 0 & 50 & 62 & 1134 & 175 & 447 & 416 & 490 & 190 \\
\hline 6 & 0 & 0 & 50 & 62 & 1200 & 179 & 515 & 432 & 511 & 173 \\
\hline 7 & 0 & 0 & 50 & 62 & 1073 & 202 & 504 & 396 & 478 & 221 \\
\hline 8 & -1.41 & 0 & 0 & 62 & 715 & 68 & 221 & 118 & 266 & 75 \\
\hline 9 & 0 & 1.41 & 50 & 100 & 1528 & 272 & 887 & 666 & 775 & 561 \\
\hline 10 & 1.41 & 0 & 100 & 62 & 1022 & 180 & 312 & 480 & 179 & 236 \\
\hline 11 & 0 & -1.41 & 50 & 25 & 1246 & 193 & 667 & 444 & 505 & 290 \\
\hline
\end{tabular}

a TEAC: Trolox equivalent antioxidant capacity. Values are expressed as mean of triplicates.

MW is the molecular weight of malvidin 3-glucoside $(494 \mathrm{~g} / \mathrm{mol})$, $\mathrm{DF}$ is the dilution factor, 1000 is used to convert $\mathrm{g}$ to $\mathrm{mg}, \varepsilon$ is the coefficient of molar absorptivity of malvidin 3-glucoside (36,400), and 1 is the optical path in $\mathrm{cm}$. The final results were obtained by correcting the mass of the winery by-products used in the extraction.

\subsubsection{Identification and quantification of phenolic compounds by} reversed-phase high performance liquid chromatography (RP-HPLC)

High performance liquid chromatography (HPLC) analyses were carried out using an analytical HPLC unit, equipped with Shimadzu ODS-A column $(4.6 \mathrm{~mm} \times 250 \mathrm{~mm}, 5 \mu \mathrm{m})$ and photodiode array detector (SPD-M10AVp, Shimadzu Co., Kyoto, Japan). Aliquots of $20 \mu \mathrm{L}$ of by-product extracts were injected in the HPLC system at a flow rate of $1.0 \mathrm{~mL} / \mathrm{min}$. For the analyses of all phenolic compounds, except anthocyanins, the mobile phase consisted of water/formic acid (99.9/0.1, v/v) (A) and acetonitrile/formic acid $(99.9 / 0.1, v / v)(B)$, starting with $5 \% \mathrm{~B}$ and increasing to $7 \% \mathrm{~B}$ (7 min), 20\% B (50 min), 45\% B (70 min), 100\% B (85 min), held at $100 \% \mathrm{~B}$ for $10 \mathrm{~min}$, and decreasing to $5 \% \mathrm{~B}$ (100 min). For the analyses of anthocyanins, the mobile phase consisted of water/formic acid $(90 / 10, v / v)(A)$ and methanol (B), starting with $5 \%$ B and increasing to $60 \%$ B (20 min), $100 \%$ B (25 min), held at $100 \%$ B for $5 \mathrm{~min}$, and decreasing to $5 \% \mathrm{~B}$ (38 min). The column was maintained at a constant temperature of $28^{\circ} \mathrm{C}$. The chromatograms were analyzed using Class-VP ${ }^{\circledR}$ software. The following authentic standards (Sigma-Aldrich, St. Louis, MO, USA) were examined: gallic acid, syringic acid, procyanidin B1, procyanidin B2, catechin, epicatechin, epicatechin-3-O-gallate, quercetin-3- $\beta$-D-glucoside, peonidin-3-O-glucoside, malvidin-3-O-glucoside, and delphinidin3-O-glucoside. Limits of detection and quantification (LOD and LOQ) were calculated using the following equations, respectively:

LOD $=3.3 \times s \div S$

$\mathrm{LOQ}=10 \times S \div S$

where $s$ is the estimated standard deviation of the linear coefficient of the equation and $S$ is the slope of the analytical curve.

\subsection{Antioxidant capacity against synthetic free radicals and reactive oxygen species (ROS)}

\subsubsection{Scavenging of synthetic free radicals DPPH' and ABTS ${ }^{+}$}

The measurement of DPPH free radical scavenging activity followed the method described by Al-Duais et al. (2009) with some modifications. Aliquots of $66 \mu \mathrm{L}$ of the standard, control, or samples and $134 \mu \mathrm{L}$ of $150 \mu \mathrm{M}$ ethanol solution of DDPH were transferred to microplate wells. The plate remained for $45 \mathrm{~min}$ in the dark and, after that, the absorbance was measured at $517 \mathrm{~nm}$ in a microplate reader (Molecular Devices, LLC, Sunnyvale, CA, USA). Ethanol was used as blank and Trolox was employed at concentrations ranging from 20 to $140 \mu \mathrm{M}$ to construct a calibration curve. The results were expressed as $\mu \mathrm{mol}$ Trolox equivalents per $\mathrm{g}$ of winery by-product.

The antioxidant capacity was determined by free radical ABTS according to Al-Duais et al. (2009) with modifications. The ABTS radical was diluted with75 $\mathrm{mM}$ potassium phosphate buffer $(\mathrm{pH}$ 7.4 ) to an absorbance of $0.700 \pm 0.01$ at $734 \mathrm{~nm}$. Aliquots of $20 \mu \mathrm{L}$ of Trolox or winery by-product extracts and $220 \mu \mathrm{L}$ of ABTS radical solution were transferred to microplate wells and kept at room temperature in the dark. The absorbance was read at $734 \mathrm{~nm}$ after 6 min of the reaction using the potassium phosphate buffer as a blank. Trolox was used as a standard at concentrations ranging from 12.5 to $200 \mu \mathrm{M}$ and the results were expressed as $\mu \mathrm{mol}$ Trolox equivalents per $g$ of winery by-product.

\subsubsection{Reactive oxygen species (ROS): peroxyl radicals (ROO'),} superoxide anion $\left(\mathrm{O}_{2}^{-}\right)$, and hypochlorous acid $(\mathrm{HOCl})$ scavenging assays

The ROO scavenging capacity was determined according to Chisté et al. (2011) with alterations. This assay was employed to monitor the antioxidant action of the winery by-product extracts on the fluorescence decay by ROO-induced oxidation of fluorescein and expressed as the oxygen radical absorbance capacity (ORAC). Aliquots of $30 \mu \mathrm{L}$ of the standard, control, or samples, $60 \mu \mathrm{L}$ of $508.25 \mathrm{nM}$ fluorescein, and $110 \mu \mathrm{L}$ of a solution of $76 \mathrm{mM}$ AAPH were transferred to a microplate. The solutions were diluted with $75 \mathrm{mM}$ potassium phosphate buffer ( $\mathrm{pH} 7.4$ ), also used as blank. The reaction was performed at $37^{\circ} \mathrm{C}$ and the absorbance was measured every minute for $2 \mathrm{~h}$ at 485 and $528 \mathrm{~nm}$, the wavelengths of excitation and emission, respectively, using a microplate reader (Molecular Devices, LLC, Sunnyvale, CA, USA). Trolox was used as a standard at concentrations ranging from 12.5 to $400 \mu \mathrm{M}$ and the results were expressed as $\mu \mathrm{mol}$ Trolox equivalents per $\mathrm{g}$ of winery by-product.

The capacity of winery by-products to scavenge the superoxide radical $\left(\mathrm{O}_{2}^{-}\right)$, generated by the $\mathrm{NADH} / \mathrm{PMS}$ system, was determined according to Gomes et al. (2007) and Chisté et al. (2011) with modifications. For a final volume of $300 \mu \mathrm{L}, 166 \mu \mathrm{M} \mathrm{NADH}$, $107.5 \mu \mathrm{M}$ NBT, different concentrations of winery by-product extracts, and $2.7 \mu \mathrm{M}$ PMS were added and dissolved in $19 \mathrm{mM}$ potassium phosphate buffer ( $\mathrm{pH} 7.4$ ). The assay was conducted at $25^{\circ} \mathrm{C}$ and after $5 \mathrm{~min}$ the absorbance was measured at $560 \mathrm{~nm}$. A control was prepared replacing the sample with buffer 
and a blank was prepared for each sample dilution replacing PMS and NADH with buffer. The results were expressed as $\mathrm{EC}_{50}$, i.e. the mean quantity $(\mathrm{mg} / \mathrm{mL})$ of winery by-product extract required to quench $50 \%$ of the superoxide radicals.

The HOCl-scavenging capacity was measured by monitoring the effects of the winery by-product extracts on HOCl-induced oxidation of dihydrorhodamine 123 (DHR) to rhodamine 123, according to Gomes et al. (2007) and Chisté et al. (2011) with modifications. $\mathrm{HOCl}$ was prepared using a $1 \% \mathrm{NaOCl}$ solution, adjusting the $\mathrm{pH}$ to 6.2 by adding $10 \% \mathrm{H}_{2} \mathrm{SO}_{4}$ solution. The concentration of this solution, diluted in $100 \mathrm{mM}$ phosphate buffer ( $\mathrm{pH} 7.4$ ), was measured at $235 \mathrm{~nm}$, using the molar absorption coefficient $100 \mathrm{M}^{-1} \mathrm{~cm}^{-1}$. A stock solution of DHR diluted in $1.15 \mathrm{mM}$ dimethylformamide was used to prepare the working solutions in phosphate buffer, immediately before the analysis. The reaction mixture contained the winery by-product extracts at different concentrations, $100 \mathrm{mM}$ phosphate buffer ( $\mathrm{pH} 7.4$ ), $1.25 \mu \mathrm{M}$ DHR, and $5 \mu \mathrm{M} \mathrm{HOCl}$, in a final volume of $300 \mu \mathrm{L}$. The assay was conducted at $37{ }^{\circ} \mathrm{C}$ in a microplate reader (Molecular Devices, LLC, Sunnyvale, CA, USA) and the fluorescence was measured immediately using the emission wavelength $528 \pm 20 \mathrm{~nm}$ with excitation at $485 \pm 20 \mathrm{~nm}$. The results were expressed as $\mathrm{EC}_{50}(\mathrm{mg} / \mathrm{mL})$ of winery by-product extract.

\subsection{Cytotoxicity assay and quantification of TNF- $\alpha$ production in RAW 264.7 cells}

\subsubsection{Cell culture}

Mouse macrophage RAW 264.7 cells from the American Type Culture Collection (ATCC, Rockville, MD, USA) were cultured in DMEM supplemented with $10 \% \mathrm{FBS}, 100 \mathrm{U} / \mathrm{mL}$ penicillin, and $100 \mu \mathrm{g} / \mathrm{mL}$ streptomycin at $37^{\circ} \mathrm{C}$ in a humidified atmosphere of $5 \% \mathrm{CO}_{2} / 95 \%$ air.

\subsubsection{Cell viability}

Cell viability was assessed using a modified MTT assay. Briefly, cells $\left(1 \times 10^{5}\right.$ cells/well) were seeded in 96-well plates and incubated at $37^{\circ} \mathrm{C}$ in a humidified atmosphere of $5 \% \mathrm{CO}_{2}$. After $24 \mathrm{~h}$ the winery by-product extracts were added at the concentrations of $0.1,0.5,1,5,10,50$, and $100 \mu \mathrm{g} / \mathrm{mL}$. After $48 \mathrm{~h}$, aliquots of $100 \mu \mathrm{L}$ of MTT solution ( $3 \mathrm{mg} / \mathrm{mL}$ in DMEM) were added to each well and further incubated for $3 \mathrm{~h}$ at $37^{\circ} \mathrm{C}$ in a humidified atmosphere of $5 \% \mathrm{CO}_{2}$. Subsequently, aliquots of $100 \mu \mathrm{L}$ of ethanol were added to each well to dissolve any deposited formazan. The optical density (OD) of each well was measured at $540 \mathrm{~nm}$ with a microplate reader (ASYS, UVM340, Biochrom, UK).

\subsubsection{Quantification of TNF- $\alpha$ production}

After 1-h exposure of the cell culture to $10 \mu \mathrm{g} / \mathrm{mL}$ of winery byproduct extracts, the samples were stimulated with $E$. coli LPS at a concentration of $10 \mathrm{ng}$ LPS per mL phosphate-buffered saline (PBS) (inflammatory stimulus) and incubated $4 \mathrm{~h}$ in an incubator with moist atmosphere of $5 \% \mathrm{CO}_{2}$ at $37^{\circ} \mathrm{C}$. Quantification of TNF- $\alpha$ was performed by ELISA on culture supernatant using protocols supplied by the manufacturer (R\&D Systems, Inc). The results are expressed as picograms.

\subsection{Statistical analysis}

All determinations were carried out in triplicate and the results were expressed as means \pm standard deviation (SD). Statistical analysis of RSM experimental data was performed with the Statistica software, version 11.0 (StatSoft Inc., 2011, Tulsa, OK, USA). The optimal conditions of extraction were estimated through three-dimensional response surface plots. Data were analyzed using
ANOVA $(p<0.05)$ and the Tukey test was applied to the antioxidant activity, cytotoxicity, and TNF- $\alpha$ quantification assays.

\section{Results and discussion}

\subsection{Optimization of winery by-products extraction}

The lyophilized winery by-products were submitted to extraction according to the conditions established for each assay in the experimental design and the results of antioxidant capacity, obtained by reduction of ABTS radical, are shown in Table 1.

The three-dimensional response surface plots generated for each type of winery by-product are presented in Fig. 1. In all samples, the quadratic terms of the variable percentage of ethanol produced negative or not significant effects, i.e. the increase in ethanol concentration did not correspond to a proportional increase in the antioxidant capacity.

The highest levels of antioxidant capacity were obtained at moderate ethanol concentrations $(40-60 \%, v / v)$ and higher temperatures. This means that an increase in the extraction temperature resulted in an increase in the studied response. For Petit Verdot pomace, although a region of higher antioxidant extraction was also observed at low temperatures, the effect of the linear term of this variable was lower than that found for its quadratic term.

Analysis of variance evidenced that for all the models, except Syrah rachis extract, lack-of-fit was not significant $(p<0.05)$. For Chenin Blanc rachis and Syrah pomace extracts the models were predictive, i.e. they can be used to predict the responses. The coefficients of determination $\left(R^{2}\right)$ ranged from 0.80 to 0.95 , indicating the adequacy of the models (Table 2 ).

During the extraction process, the fraction of interest is dependent on the type of solvent, due to the polarity relationship established. Higher polarity solvents, as those employed in this study, are more efficient to extract polar substances, such as phenolic compounds and great part of the antioxidant compounds, as well as those substances that require hydrogen bond breaking or electrostatic force to be extracted (Tir, Dutta, \& Badjah-Hadj-Ahmed, 2012).

Heating favors the process of extraction of winery by-products, since it increases the solute diffusion ratio, accelerating the transference of mass, solubilizing compounds, and reducing solute-matrix interactions (Monrad, Howard, King, Srinivas, \& Mauromoustakos, 2010).

During the aqueous extraction of anthocyanins from grape pomaces, it was observed that heating $\left(140{ }^{\circ} \mathrm{C}\right)$ is of fundamental importance to increase the elution of these natural pigments, because it promotes higher diffusibility and solubilization of these molecules in the extraction solvent (Monrad, Srinivas, Howard, \& King, 2012). Moderate concentrations of ethanol (40-55\%, v/v) and temperature of $84{ }^{\circ} \mathrm{C}$ were the conditions for the highest antioxidant activity of grape rachis extracts (Karacabey \& Mazza, 2010).

After the analysis of the response surface plots (Fig. 1), two different concentrations of ethanol $(43 \%$ and $57 \%$, v/v) were established, which represented the lowest percentages of this solvent within the optimum range of extraction of each by-product. This selection criterion was adopted aiming to restrict the use of ethanol. Therefore, $43 \%$ of ethanol was used for the extraction of Petit Verdot and Syrah rachis, and 57\% of ethanol was employed for the extraction of Chenin Blanc, Petit Verdot, and Syrah pomaces, as well as Chenin Blanc rachis. To determine the temperature of extraction the lowest temperature within the optimum range of extraction of each by-product was chosen, which was established as $96{ }^{\circ} \mathrm{C}$. 

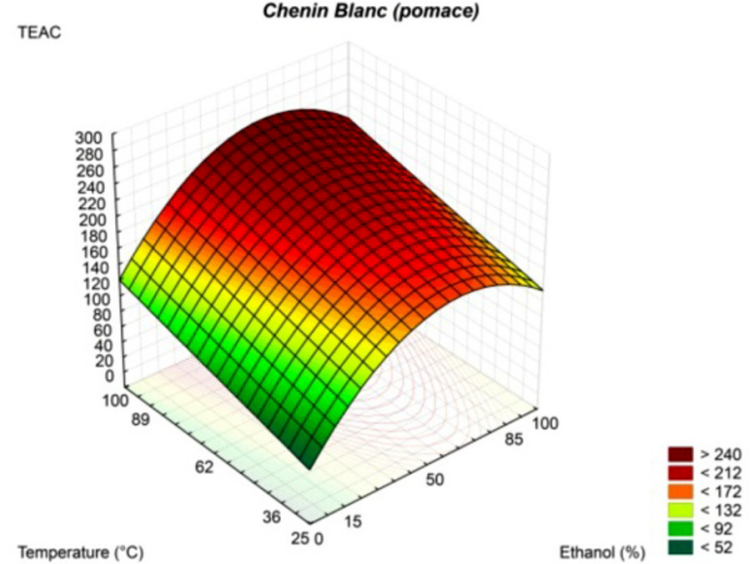

$z=205.53311014168+29.580955342143^{\star} x-39.790565878304^{*} x^{\wedge} 2+25.047844713021^{*} y+0$
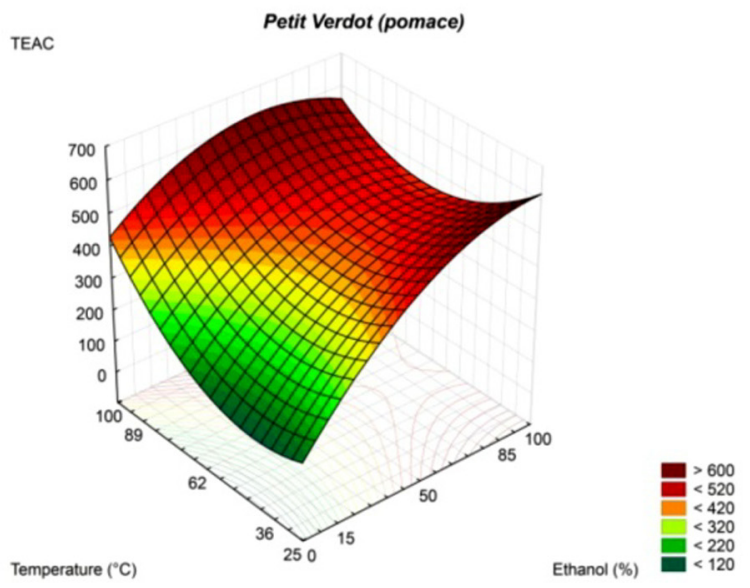

$z=415.31773946378+107.47070600035^{\star} x-58.997140434728^{\star} x^{\wedge} 2+39.019651989669^{*} y+$ $69.916681807614^{*} y^{\wedge} 2-43.14363^{*} x^{*} y+0$
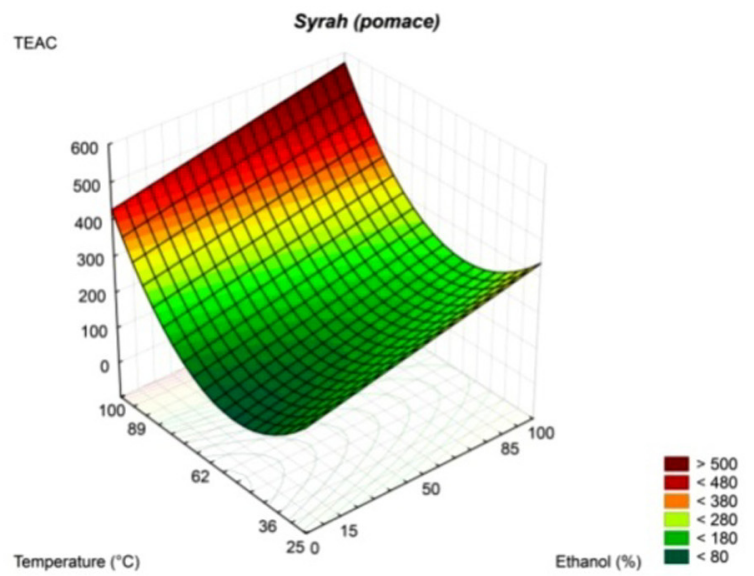

$z=161.77527809834+51.573892768486^{*} x+83.074411775031^{*} y+110.34441976358^{*} y^{\wedge} 2+0$

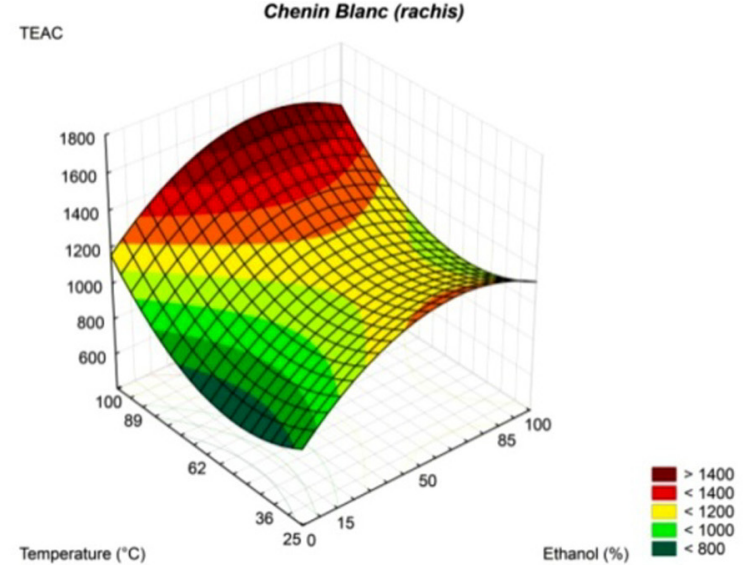

$z=1136.230418231+106.3733808079^{*} x-129.72799769594^{\star} x^{\wedge} 2+117.39440936787^{\star} y+$ $131.17577978005^{\star} y^{\wedge} 2+0$

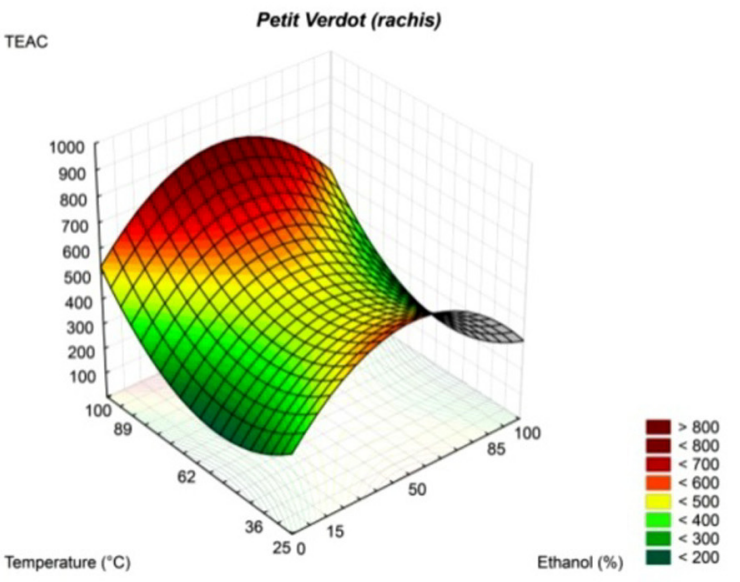

$z=489.75502945549-145.47853398974^{*} x^{\wedge} 2+74.125068077531^{\star} y+111.17867641215^{*} y^{\wedge} 2+0$

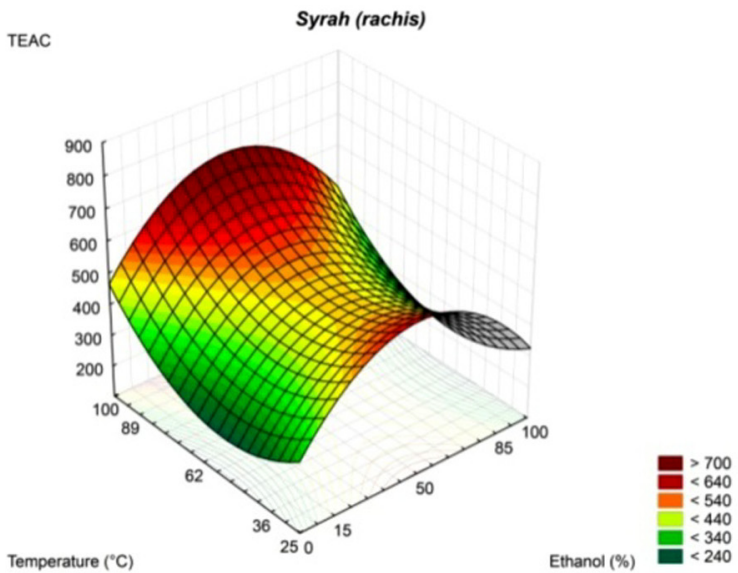

$z=493.04214307945-129.62505890376^{*} x^{\wedge} 2+48.989772209824^{*} y+80.321402541841^{\star} y^{\wedge} 2+0$

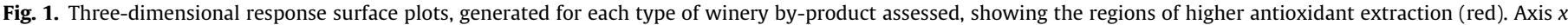

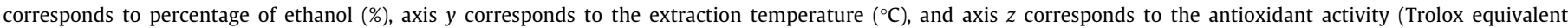

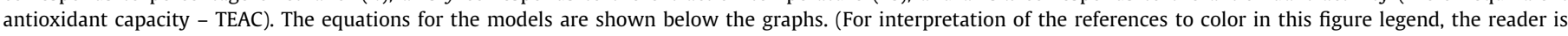
referred to the web version of this article.) 
Table 2

Analysis of variance applied to the effects of the variables temperature and percentage of ethanol on the antioxidant activity of different types of winery byproducts.

\begin{tabular}{|c|c|c|c|c|c|}
\hline Parameter & $R^{2}$ & $\begin{array}{l}\text { Quadratic } \\
\text { sum (QS) }\end{array}$ & $\begin{array}{l}\text { Degrees of } \\
\text { freedom }(\mathrm{df})\end{array}$ & $\begin{array}{l}\text { Quadratic } \\
\text { mean (QM) }\end{array}$ & $F$-test \\
\hline \multicolumn{6}{|l|}{ Chenin Blanc } \\
\hline Rachis & 0.95 & & & & \\
\hline Regression & & 469,233 & 4 & 117,308 & $28.35^{*}$,a \\
\hline $\begin{array}{l}\text { By- } \\
\text { product }\end{array}$ & & 24,825 & 6 & 4137 & \\
\hline Lack-of-fit & & 16,675 & 4 & 4168 & 1.02 \\
\hline Pure error & & 8150 & 2 & 4075 & \\
\hline Total & & 494,059 & 10 & & \\
\hline Pomace & 0.84 & & & & \\
\hline Regression & & 21,675 & 3 & 7225 & $12.37^{*}$ \\
\hline $\begin{array}{l}\text { By- } \\
\text { product }\end{array}$ & & 4088 & 7 & 584 & \\
\hline Lack-of-fit & & 3657 & 5 & 731 & 3.39 \\
\hline Pure error & & 431 & 2 & 215 & \\
\hline Total & & 25,764 & 10 & & \\
\hline \multicolumn{6}{|l|}{ Petit Verdot } \\
\hline Rachis & 0.82 & & & & \\
\hline Regression & & 306,742 & 3 & 102,247 & $10.48^{*}$ \\
\hline $\begin{array}{l}\text { By- } \\
\text { product }\end{array}$ & & 68,282 & 7 & 9754 & \\
\hline Lack-of-fit & & 65,597 & 5 & 13,119 & 9.77 \\
\hline Pure error & & 2685 & 2 & 1342 & \\
\hline Total & & 375,025 & 10 & & \\
\hline Pomace & 0.91 & & & & \\
\hline Regression & & 177,659 & 5 & 35,531 & $10.69^{*}$ \\
\hline $\begin{array}{l}\text { By- } \\
\text { product }\end{array}$ & & 16,622 & 5 & 3324 & \\
\hline Lack-of-fit & & 15,979 & 3 & 5326 & 16.57 \\
\hline Pure error & & 643 & 2 & 321 & \\
\hline Total & & 194,282 & 10 & & \\
\hline \multicolumn{6}{|l|}{ Syrah } \\
\hline Rachis & 0.80 & & & & \\
\hline Regression & & 198,633 & 4 & 49,658 & $5.60^{*}$ \\
\hline $\begin{array}{l}\text { By- } \\
\text { product }\end{array}$ & & 49,679 & 6 & 8279 & \\
\hline Lack-of-fit & & 49,113 & 5 & 9822 & $34.68^{*}$ \\
\hline Pure error & & 566 & 2 & 283 & \\
\hline Total & & 248,313 & 10 & & \\
\hline Pomace & 0.89 & & & & \\
\hline Regression & & 150,796 & 3 & 50,265 & $19.19^{*}, \mathrm{a}$ \\
\hline $\begin{array}{l}\text { By- } \\
\text { product }\end{array}$ & & 18,332 & 7 & 2618 & \\
\hline Lack-of-fit & & 17,152 & 5 & 3430 & 5.81 \\
\hline Pure error & & 1180 & 2 & 590 & \\
\hline Total & & 169,129 & 10 & & \\
\hline
\end{tabular}

Significant $(p<0.05)$

a Predictive model.

\subsection{Determination of phenolic compounds}

\subsubsection{Content of total phenolic compounds and anthocyanins}

Rachis extracts presented higher contents of phenolic compounds compared to pomace extracts, and the highest concentration was registered for the white variety Chenin Blanc.

The total phenolic content of Syrah, Cabernet Sauvignon, and Merlot red wines ranged from 48 to $56 \mathrm{mg} / \mathrm{g}$ of dry wine (GAE) (Ivanova-Petropulos et al., 2015), a content equivalent to the Syrah and Petit Verdot red pomaces studied (39 and $66 \mathrm{mg} / \mathrm{g}$ ), but lower than Chenin Blanc, Petit Verdot, and Syrah rachis, which ranged from 50 to $124 \mathrm{mg} / \mathrm{g}$ (GAE) (Table 3). Although phenolic compounds are transferred to the wine during the winemaking process, a considerable amount of these compounds still remains in the pomaces and is concentrated in the rachis.

The highest content of total anthocyanins was found in red varieties Syrah and Petit Verdot pomace extracts, in this order. No anthocyanins were detected in by-products from the white variety Chenin Blanc (Table 3).
While the transference of other phenolic compounds to wine is lower, the extraction of anthocyanins from the grapes during the winemaking process seems to be more efficient. According to Ivanova-Petropulos et al. (2015), Syrah, Cabernet Sauvignon, and Merlot red wines had a content of total anthocyanins ranging from 19 to $22 \mathrm{mg} / \mathrm{g}$ of dry wine, while the red pomaces of this study retained from 0.99 to $1.41 \mathrm{mg} / \mathrm{g}$ of total anthocyanins.

In fact, some winery by-products, produced in semi-arid regions worldwide, have already been considered potential sources of phenolic compounds, especially stilbenes and flavonoids (Katalinic et al., 2010).

In a study conducted in China, wines produced from grapes grown in geographically different regions presented differences in their profile of phenolic compounds. Wine samples from drier areas in Western China had lower content of total anthocyanins and higher contents of kaempferol derivates and hydroxycinnamic acids than wines produced with grapes cultivated in other regions (Li, Pan, Jin, Mu, \& Duan, 2011). In addition to grape variety, some environmental factors such as temperature, ultraviolet radiation, and nutrient supply can affect the metabolism and regulate the gene expression of flavonoid in grapes (Cohen, Tarara, Gambetta, Matthews, \& Kennedy, 2012; Martínez-Lüscher et al., 2014; Soubeyrand et al., 2014), leading to differences in the phenolic profile of wines and, consequently, in their by-products.

\subsubsection{Identification and quantification of phenolic compounds by} reversed-phase high performance liquid chromatography (RP-HPLC)

After the extraction process of the winery by-products under study, it was possible to identify eleven phenolic compounds, distributed in five different classes: gallic and syringic acids (hydroxybenzoic acids), procyanidins B1 and B2 (proanthocyanidins), catechin, epicatechin, epicatechin gallate (flavan-3-ols), quercertin 3- $\beta$-D-glucoside (flavonol), and delfinidin 3-glucoside, peonidin 3-O-glucoside, and malvidin 3-glucoside (anthocyanins) (Table 3).

Catechin, procyanidin B1, epicatechin, and gallic acid presented the highest occurrence, since they were identified in all the winery by-product extracts analyzed. Procyanidin B2 was identified only in pomace extracts, whereas syringic acid was only found in pomace extracts from red grapes.

The total contents of polyphenols identified in by-product extracts from Chenin Blanc were $1.14 \mu \mathrm{g} / \mathrm{mg}$ and $10.36 \mu \mathrm{g} / \mathrm{mg}$ for pomace and rachis, respectively. A higher content of phenolic compounds was detected in by-product extracts from red grapes Petit Verdot and Syrah, with $18.03 \mu \mathrm{g} / \mathrm{mg}$ and $5.71 \mu \mathrm{g} / \mathrm{mg}$ in pomace, and $9.06 \mu \mathrm{g} / \mathrm{mg}$ and $5.89 \mu \mathrm{g} / \mathrm{mg}$ in rachis, respectively.

In by-product extracts obtained from the white grape variety Chenin Blanc, gallic acid (pomace and rachis), procyanidins B1 (pomace and rachis) and B2 (pomace), catechin, epicatechin (pomace and rachis), epicatechin gallate, and quercetin $3-\beta-D-g l u-$ coside (pomace) were identified and quantified. Although a higher number of polyphenols was identified in Chenin Blanc pomace extract, the concentrations of gallic acid, procyanidin B1, and catechin were 3-, 28-, and 17-fold higher in rachis extract than in pomace, respectively.

In by-product extracts from Petit Verdot and Syrah, gallic acid (pomace and rachis), syringic acid (pomace), procyanidins B1 (pomace and rachis) and B2 (pomace), catechin, epicatechin (pomace and rachis), and quercetin 3- $\beta$-D-glucoside (Syrah pomace) were identified and quantified. Unlike the results obtained for the samples of Chenin Blanc, the pomace extracts from the red grape varieties presented high contents of catechin and epicatechin (Table 3). The content of catechin we found in Petit Verdot pomace was superior to those registered for Syrah and Cabernet Sauvignon red wines, which were around $6 \mathrm{mg} / \mathrm{g}$ of dry wine (Ivanova-Petropulos et al., 2015). Also, we found highest 
Table 3

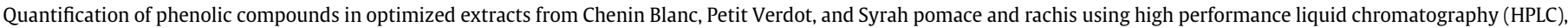
Folin-Ciocalteau (TPC) and total monomeric anthocyanin (TMA) methods.

\begin{tabular}{|c|c|c|c|c|c|c|c|c|c|}
\hline \multirow[t]{3}{*}{ Phenolic compound ( $\mu \mathrm{g} / \mathrm{mg})$} & \multicolumn{6}{|c|}{ Winery by-products } & \multirow{2}{*}{\multicolumn{3}{|c|}{ Validation parameters }} \\
\hline & \multicolumn{2}{|l|}{ Chenin Blanc } & \multicolumn{2}{|l|}{ Petit Verdot } & \multicolumn{2}{|l|}{ Syrah } & & & \\
\hline & Rachis & Pomace & Rachis & Pomace & Rachis & Pomace & $\mathrm{LOD}^{4}(\mu \mathrm{g})$ & $\mathrm{LOQ}^{5}(\mu \mathrm{g})$ & Linearity $\left(R^{2}\right)$ \\
\hline $\begin{array}{l}\text { Hydroxybenzoic acid } \\
\text { Gallic acid } \\
\text { Syringic acid }\end{array}$ & $\begin{array}{l}0.15 \pm 0.02 \\
\text { nd }^{3}\end{array}$ & $\begin{array}{l}0.05 \pm 0.00 \\
\text { nd }\end{array}$ & $\begin{array}{l}0.14 \pm 0.01 \\
\text { nd }\end{array}$ & $\begin{array}{l}0.84 \pm 0.04 \\
0.13 \pm 0.01\end{array}$ & $\begin{array}{l}0.99 \pm 0.00 \\
\text { nd }\end{array}$ & $\begin{array}{l}0.43 \pm 0.01 \\
0.04 \pm 0.00\end{array}$ & $\begin{array}{l}0.0052 \\
0.0007\end{array}$ & $\begin{array}{l}0.0160 \\
0.0022\end{array}$ & $\begin{array}{l}0.997 \\
0.998\end{array}$ \\
\hline $\begin{array}{l}\text { Proanthocyanidin } \\
\text { Procyanidin B1 } \\
\text { Procyanidin B2 }\end{array}$ & $\begin{array}{l}5.93 \pm 0.58 \\
\text { nd }\end{array}$ & $\begin{array}{l}0.21 \pm 0.01 \\
0.15 \pm 0.01\end{array}$ & $\begin{array}{l}3.04 \pm 0.15 \\
\text { nd }\end{array}$ & $\begin{array}{l}1.93 \pm 0.06 \\
1.89 \pm 0.15\end{array}$ & $\begin{array}{l}2.09 \pm 0.02 \\
\text { nd }\end{array}$ & $\begin{array}{l}0.84 \pm 0.06 \\
0.77 \pm 0.04\end{array}$ & $\begin{array}{l}0.0046 \\
0.0059\end{array}$ & $\begin{array}{l}0.0140 \\
0.0180\end{array}$ & $\begin{array}{l}1.000 \\
0.999\end{array}$ \\
\hline $\begin{array}{l}\text { Flavan-3-ol } \\
\text { Catechin } \\
\text { Epicatechin } \\
\text { Epicatechin gallate }\end{array}$ & $\begin{array}{l}4.11 \pm 0.03 \\
0.17 \pm 0.01 \\
\text { nd }\end{array}$ & $\begin{array}{l}0.24 \pm 0.10 \\
0.32 \pm 0.05 \\
0.08 \pm 0.01\end{array}$ & $\begin{array}{l}2.49 \pm 0.03 \\
0.04 \pm 0.00 \\
\text { nd }\end{array}$ & $\begin{array}{l}7.43 \pm 0.40 \\
5.81 \pm 0.22 \\
\text { nd }\end{array}$ & $\begin{array}{l}2.57 \pm 0.07 \\
0.24 \pm 0.01 \\
\text { nd }\end{array}$ & $\begin{array}{l}3.43 \pm 0.26 \\
3.11 \pm 0.12 \\
\text { nd }\end{array}$ & $\begin{array}{l}0.0380 \\
0.0087 \\
0.0032\end{array}$ & $\begin{array}{l}0.110 \\
0.0260 \\
0.0098\end{array}$ & $\begin{array}{l}0.983 \\
0.999 \\
0.999\end{array}$ \\
\hline $\begin{array}{l}\text { Flavonol } \\
\text { Quercetin 3- } \beta \text {-D-glucoside }\end{array}$ & nd & $0.09 \pm 0.00$ & nd & nd & nd & $0.44 \pm 0.02$ & 0.0068 & 0.0210 & 0.999 \\
\hline $\begin{array}{l}\text { Anthocyanin } \\
\text { Delfinidin 3-glucoside } \\
\text { Peonidin 3-O-glucoside } \\
\text { Malvidin 3-glucoside } \\
\text { TPC }^{1} \\
\text { TMA }^{2}\end{array}$ & $\begin{array}{l}\text { nd } \\
\text { nd } \\
\text { nd } \\
124.96 \pm 6.40^{\mathrm{a}} \\
\text { nd }\end{array}$ & $\begin{array}{l}\text { nd } \\
\text { nd } \\
\text { nd } \\
20.17 \pm 0.60^{\mathrm{e}} \\
\text { nd }\end{array}$ & $\begin{array}{l}\text { nd } \\
\text { nd } \\
\text { nd } \\
96.77 \pm 6.60^{b} \\
0.22 \pm 0.01 \mathrm{c}\end{array}$ & $\begin{array}{l}0.07 \pm 0.00 \\
0.04 \pm 0.00 \\
1.66 \pm 0.08 \\
66.69 \pm 7.00^{\mathrm{c}} \\
0.99 \pm 0.06^{\mathrm{b}}\end{array}$ & $\begin{array}{l}\text { nd } \\
\text { nd } \\
\text { nd } \\
50.63 \pm 2.11^{\mathrm{d}} \\
0.09 \pm 0.00^{\mathrm{d}}\end{array}$ & $\begin{array}{l}0.05 \pm 0.00 \\
0.44 \pm 0.01 \\
1.71 \pm 0.07 \\
39.30 \pm 2.37^{\mathrm{d}} \\
1.41 \pm 0.03^{\mathrm{a}}\end{array}$ & $\begin{array}{l}0.0012 \\
0.0012 \\
0.0075 \\
\text { nd } \\
\text { nd }\end{array}$ & $\begin{array}{l}0.0035 \\
0.0035 \\
0.023 \\
\text { nd } \\
\text { nd }\end{array}$ & $\begin{array}{l}0.999 \\
0.999 \\
0.999 \\
\text { nd } \\
\text { nd }\end{array}$ \\
\hline
\end{tabular}

Each value is expressed as mean (triplicate) \pm standard deviation (SD). The same letters in the row are not significantly different at the 0.05 level according to ANOVA.

1 Total phenolic compounds: expressed as $\mu \mathrm{g}$ of gallic acid equivalent per mg of lyophilized winery by-product.

2 Total monomeric anthocyanin pigment: expressed as $\mu \mathrm{g}$ of malvidin equivalent per mg of lyophilized winery by-product.

3 nd: non-detected.

4 LOD: limit of detection.

5 LOQ: limit of quantification.

concentrations of gallic acid, catechin, and epicatechin in red pomaces from the semi-arid region compared to red grape pomaces produced in a wet region in the South of Brazil, in which some of these phenolic compounds were also reported (Rockenbach et al., 2011). In fact, Li et al. (2011) concluded that Cabernet Sauvignon red wine produced with grapes grown in drier areas had the highest level of epicatechin compared to other climatic regions.

Anthocyanins were identified and quantified using HPLC only in red grape pomace extracts, due to the lower content of these compounds in rachis compared to pomace extracts, according to the results obtained for total anthocyanins (TMA) (Table 3).

Syrah pomace extract showed higher contents of the anthocyanins peonidin 3-O-glucoside and malvidin 3-glucoside compared to Petit Verdot pomace extract. However, regardless of grape variety, malvidin 3-glucoside was the anthocyanin present in highest concentrations, with 1.66 and $1.77 \mu \mathrm{g} / \mathrm{mg}$ in Petit Verdot and Syrah by-product extracts, respectively. Malvidin 3-O-glucoside was also the main anthocyanin found in Nerello Mascalese grape pomace $(64.6 \mathrm{mg} / \mathrm{kg}$ ) (Amico et al., 2004) as well as in Syrah, Cabernet Sauvignon, and Merlot wines (Ivanova-Petropulos et al., 2015)

Wang, Tong, Chen, and Gangemi (2010) identified ellagic acid, gallic acid, (-)-epicatechin, (-)-epigallocatechin, catechin, myricetin, quercetin, and kaempferol in the extract of grape variety Muscadine, and several of these compounds were also identified in the present study. Therefore, winery by-products obtained in semiarid regions can also be important sources of phenolic compounds.

\subsection{Antioxidant capacity}

\subsubsection{Scavenging of synthetic free radicals DPPH and ABTS and} reactive oxygen species (ROS; peroxyl radical, superoxide anion, and hypochlorous acid)

Using methods based on synthetic free radicals, DPPH and ABTS, Chenin Blanc rachis extract showed the best performance, with
1086 and $2419 \mu \mathrm{mol} / \mathrm{g}$, respectively, followed by the red grapes rachis and pomace extracts (Table 4 ).

Other studies also registered the antioxidant activity of the same synthetic radicals in Muscadine (Wang, Tong, et al., 2010) and Cabernet Sauvignon (Rubilar, Pinelo, Shene, Sineiro, \& Nuñez, 2007) pomaces, but no analyses were carried out in the respective rachis. And according to the results obtained in the present work, rachis extracts showed higher antioxidant activity.

In our study, the capacity of inactivation of reactive species derived from radical oxygen, such as peroxyl (ROO') and superoxide $\left(\mathrm{O}_{2}^{-}\right)$, as well as from non-radical oxygen, such as hypochlorous acid, was also evaluated. These reactive species are generated in biological systems and are involved in lipid peroxidation and oxidative stress (Sánchez-Moreno, 2002).

Peroxyl radical is slightly less reactive than hydroxyl radical (HO) (Alves, David, David, Bahia, \& Aguiar, 2010) and, although it is formed during the propagation phase in lipid peroxidation, it can also be formed from non-lipid substrates, such as proteins, in biological systems (Dean, Fu, Stocker, \& Davies, 1997; Halliwell, Aeschbach, Löliger, \& Aruoma, 1995).

All the winery by-product extracts, except Chenin Blanc pomace, presented high scavenging capacity against peroxyl radical, and once more Chenin Blanc rachis stood out as the best (Table 4). The scavenging capacity against peroxyl radical exhibited by grape pomace and rachis extracts in the present study was higher than that observed by Chisté et al. (2011) for Bixa orellana L. (annatto) seed extracts and bixin standard. Although the results obtained for the winery by-product extracts were lower than those found for the standards gallic acid $(13,783 \mu \mathrm{mol} / \mathrm{g})$ and epicatechin $(32,163 \mu \mathrm{mol} / \mathrm{g})$, they presented higher scavenging capacity against peroxyl radical than that reported by Rodrigues, Mariutti, and Mercadante (2013) for Solanum sessiliflorum (mana-cubiu) extract $(320 \mu \mathrm{mol} / \mathrm{g})$. Also, the results herein obtained for Chenin Blanc rachis extract were similar to the capacity exhibited by the standard Trolox $(4030 \mu \mathrm{mol} / \mathrm{g})$ in the study performed by Rodrigues et al. (2013). 
Table 4

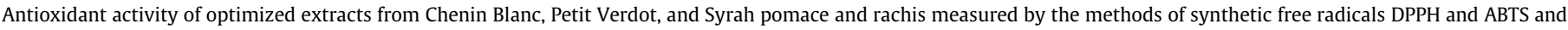
against reactive oxygen species (ROS; peroxyl, superoxide, and hypochlorous acid).

\begin{tabular}{|c|c|c|c|c|c|}
\hline \multirow[t]{2}{*}{ Parameter } & \multicolumn{2}{|c|}{ Synthetic free radical } & \multicolumn{3}{|l|}{ ROS } \\
\hline & $\begin{array}{l}\mathrm{DPPH} \cdot(\mu \mathrm{mol} / \\
\mathrm{g})^{1}\end{array}$ & $\begin{array}{l}\text { ABTS }^{+}(\mu \mathrm{mol} / \\
\mathrm{g})^{1}\end{array}$ & $\begin{array}{l}\text { Peroxyl radical (ROO·) ( } \mu \mathrm{mol} / \\
\mathrm{g})^{1}\end{array}$ & $\begin{array}{l}\text { Superoxide radical }\left(\mathrm{O}_{2}^{-}\right)\left(\mathrm{EC}_{50}, \mathrm{mg} /\right. \\
\mathrm{mL})^{2}\end{array}$ & $\begin{array}{l}\text { Hypochlorous acid ( } \mathrm{HOCl})\left(\mathrm{EC}_{50}, \mathrm{mg} /\right. \\
\mathrm{mL})^{2}\end{array}$ \\
\hline \multicolumn{6}{|l|}{ Chenin Blanc } \\
\hline Rachis & $1086 \pm 30^{\mathrm{a}}$ & $2419 \pm 113^{\mathrm{a}}$ & $3718 \pm 97^{\mathrm{a}}$ & $0.17 \pm 0.05^{c}$ & $0.021 \pm 0.001^{c}$ \\
\hline Pomace & $191 \pm 10^{\mathrm{e}}$ & $218 \pm 17^{c}$ & $739 \pm 29^{d}$ & $2.16 \pm 0.02^{\mathrm{a}}$ & $0.128 \pm 0.012^{\mathrm{a}}$ \\
\hline \multicolumn{6}{|l|}{ Petit Verdot } \\
\hline Rachis & $685 \pm 13^{b}$ & $860 \pm 14^{b}$ & $2939 \pm 269^{b}$ & $0.28 \pm 0.01^{\mathrm{b}}$ & $0.035 \pm 0.001^{\mathrm{bc}}$ \\
\hline Pomace & $540 \pm 9^{c}$ & $626 \pm 9^{b}$ & $2796 \pm 75^{b c}$ & $0.19 \pm 0.01^{\mathrm{c}}$ & $0.017 \pm 0.001^{\mathrm{c}}$ \\
\hline \multicolumn{6}{|l|}{ Syrah } \\
\hline Rachis & $473 \pm 8^{c}$ & $805 \pm 31^{b}$ & $2191 \pm 140^{c}$ & $0.26 \pm 0.01^{\mathrm{b}}$ & $0.042 \pm 0.001^{\mathrm{b}}$ \\
\hline Pomace & $310 \pm 7^{d}$ & $653 \pm 34^{b}$ & $1363 \pm 79^{d}$ & $0.24 \pm 0.01^{\mathrm{bc}}$ & $0.031 \pm 0.001^{\mathrm{bc}}$ \\
\hline Gallic acid & - & - & $13,783 \pm 1332$ & $0.07 \pm 0.00$ & $8.46 \times 10^{-3} \pm 0.00$ \\
\hline Epicatechin & - & - & $32,163 \pm 1748$ & $0.23 \pm 0.01$ & $0.81 \times 10^{-3} \pm 0.00$ \\
\hline
\end{tabular}

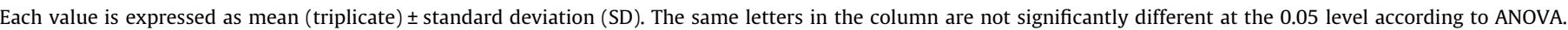

1 Expressed as $\mu \mathrm{mol}$ Trolox equivalents per $\mathrm{g}$ of lyophilized winery by-product.

${ }^{2} \mathrm{EC}_{50}$ is the mean quantity $(\mathrm{mg} / \mathrm{mL})$ of winery by-product extract required to quench $50 \%$ of ROS in the assay.

Superoxide radical is spontaneously produced in vivo in the respiratory chain and is converted by superoxide dismutase (SOD, EC 1.15.1.1) into hydrogen peroxide $\left(\mathrm{H}_{2} \mathrm{O}_{2}\right)$. Hydrogen peroxide can interact with transition metal ions to generate hydroxyl radical, which is highly oxidative and may cause serious damage to biological structures, mainly polyunsaturated fatty acids, thus generating peroxyl radical (Gomes et al., 2007).

All the winery by-product extracts assessed, except Chenin Blanc pomace, presented high scavenging capacity against superoxide anion, comparable to the capacity exhibited by ascorbic acid $(0.25 \mathrm{mg} / \mathrm{mL})$ and superior to that of BHT $(0.83 \mathrm{mg} / \mathrm{mL})$ (Kong, Mat-Junit, Aminudin, Ismail, \& Abdul-Aziz, 2012). Chenin Blanc rachis and Petit Verdot pomace extracts presented the highest capacity of deactivation of superoxide radical $(0.17$ and $0.19 \mathrm{mg} /$ $\mathrm{mL}$, respectively), and also higher than that registered for the standard epicatechin $(0.23 \mathrm{mg} / \mathrm{mL})$. The red grape pomace extracts showed higher scavenging capacity against superoxide radical than their respective rachis extracts, a fact not observed for synthetic reactive species and peroxyl radical.

Hypochlorous acid $(\mathrm{HOCl})$ is also a highly oxidative reactive species, naturally produced in neutrophils by myeloperoxidase (MPO, EC 1.11.2.2), enzyme which catalyzes the oxidation of chloride ions by hydrogen peroxide, forming hypochlorous acid. This compound acts as a defense mechanism against microorganisms phagocytosed by neutrophils, but in excess it may cause serious damage to tissues (Alves et al., 2010; Halliwell et al., 1995).

During the tests to assess the winery by-product extracts capacity to deactivate hypochlorous acid, the red grape pomace extracts presented higher capacity than their rachis extracts, and Petit Verdot pomace extract stood out as the best one $(0.017 \mathrm{mg} / \mathrm{mL})$. The present results were better than those found for Pedilanthus tithymaloides (L.) Poit. extract $(0.113 \mathrm{mg} / \mathrm{mL})$ (Abreu et al., 2006) and Trolox $(0.134 \mathrm{mg} / \mathrm{mL})$ and similar to that registered for mana-cubiu extract $(0.013 \mathrm{mg} / \mathrm{mL})$ (Rodrigues et al., 2013). Chenin Blanc rachis extract also presented a result $(0.021 \mathrm{mg} / \mathrm{mL})$ similar to Petit Verdot pomace extract $(0.017 \mathrm{mg} / \mathrm{mL})$. The standards gallic acid and epicatechin exhibited the highest capacity of deactivation of hypochlorous acid. Similarly to the results found for superoxide radical, red grape pomace extracts were more effective to deactivate hypochlorous acid than their rachis extracts, a pattern not observed for the white grape Chenin Blanc, since its rachis extract was more effective than its pomace extract against this species (Table 4).

\subsubsection{Correlation between antioxidant capacity against synthetic} radicals and reactive oxygen species

The correlation between the assays to evaluate antioxidant capacity using synthetic free radicals (direct methods) and those that generate reactive species during the reaction (indirect methods) was strong and positive for superoxide $\times$ hypochlorous acid (0.98), DPPH $\times$ peroxyl (0.94), and DPPH $\times$ ABTS (0.93). Moderate correlations were found for $A B T S \times$ peroxyl (0.79), perox$\mathrm{yl} \times$ hypochlorous acid (0.75), peroxyl $\times$ superoxide $(0.71)$, and $\mathrm{DPPH} \times$ hypochlorous acid $(0.61)$, whereas low correlations were detected for DPPH $\times$ superoxide (0.57), ABTS $\times$ hypochlorous acid (0.51), and ABTS $\times$ superoxide (0.48). Therefore, the assessment of antioxidant activity using synthetic radicals was not precise to estimate the capacity to deactivate ROS, since the response of this type of assay better reflects what happens in in vivo systems.

The correlation between the major phenolic compounds identified in winery by-product extracts and the assays to evaluate antioxidant capacity was strong and positive for procyanidin B1 using DPPH (0.99), ABTS (0.96), and peroxyl (0.91), and low using hypochlorous acid (0.57) and superoxide (0.54). These results may account for the higher antioxidant capacity of Chenin Blanc rachis extract for free radicals DPPH, ABTS, and peroxyl, because this winery by-product extract presented the highest content of this proanthocyanidin $(5.93 \mu \mathrm{g} / \mathrm{mg})$.

Among the phenolic compounds analyzed, catechin presented the highest correlation with hypochlorous acid $(0.78)$ and superoxide (0.67) assays. This may explain the good response of red grape pomace extracts in these two methods, since these winery by-product extracts showed the highest contents of catechin (7.43 and $3.43 \mu \mathrm{g} / \mathrm{mg}$ ), therefore surpassing rachis extracts in the capacity to deactivate these species.

The synthetic radicals presented weak correlation of catechin with DPPH (0.38), ABTS (0.25), and peroxyl (0.57). Gallic acid presented negative correlation with DPPH $(-0.16)$ and ABTS $(-0.21)$, and positive, although weak, correlation with peroxyl (0.07), hypochlorous acid (0.73), and superoxide (0.47). Epicatechin also had negative correlation with DPPH $(-0.22)$, ABTS $(-0.29)$, and ORAC $(-0.02)$, and positive correlation with hypochlorous acid $(0.39)$ and superoxide (0.29). In spite of presenting distinct molecular structures, gallic acid and epicatechin, as well as procyanidin B1 and catechin contributed to the antioxidant capacity in the different methods. Catechin and its isomer epicatechin exhibit differentiated antioxidant capacity against synthetic free radicals and ROS due to the tridimensional disposition of hydroxyl functional 
groups, as well as the positions of the double bonds in the benzenic rings of their molecules. The possibility of synergism between these two compounds, positive or negative, should also be taken into consideration, because they might present different activities when analyzed separately.

\subsection{Cytotoxicity assay and quantification of TNF- $\alpha$ production in RAW 264.7 cells}

The extracts obtained from grape rachis and pomace did not decrease cell viability compared to the vehicle, except for Petit Verdot pomace and Chenin Blanc rachis extracts, which significantly decreased cell viability at the concentration of 50 and $100 \mu \mathrm{g} / \mathrm{mL}$ and $100 \mu \mathrm{g} / \mathrm{mL}$ ( $p<0.05$ ), respectively (Fig. $2 \mathrm{~A}$ and E).

Cell viability was evaluated using the MTT assay after treating RAW 264.7 cells with winery by-product extracts. MTT is a tetrazolium salt which is reduced to formazan crystals mainly by mitochondrial succinate dehydrogenase (SDH, EC 1.3.3.99) (O'Toole et al., 2003). These crystals exhibit purple color, the intensity of which is proportional to the number of viable cells and can be measured spectrophotometrically at $570 \mathrm{~nm}$. The extracts herein tested presented low cytotoxicity against RAW 264.7 cells. However, some phytochemical compounds such as polyphenols may change the activity of SDH or interact with MTT directly (Wang, Henning, \& Heber, 2010). Therefore, the treatment with winery by-product extracts at some concentrations probably increased the activity of mitochondrial dehydrogenase and the intrinsic potential of polyphenols to reduce MTT and increase formazan formation.

Winery by-product extracts were not cytotoxic up to $10 \mu \mathrm{g} / \mathrm{mL}$ of all extracts tested. Therefore this concentration was used as a safe standard for all the extracts in order to quantify and compare TNF- $\alpha$ signaling during inflammatory processes, since the release of this compound is related to oxidative cell damage. Given that some cytokine inhibition can relieve inflammation, we examined the inhibitory effect of the extracts on TNF- $\alpha$ in RAW 264.7 cells upon LPS stimulation. As presented in Fig. 2C, Petit Verdot pomace was the only that suppressed TNF- $\alpha$ liberation $(p<0.05)$ at the concentration of $10 \mu \mathrm{g} / \mathrm{mL}$. Denny et al. (2014) demonstrated that the pomace obtained from Petit Verdot decreased TNF- $\alpha$ release in mice subjected to intraperitoneal injection of carrageenan, which corroborates the in vitro results obtained in this study.
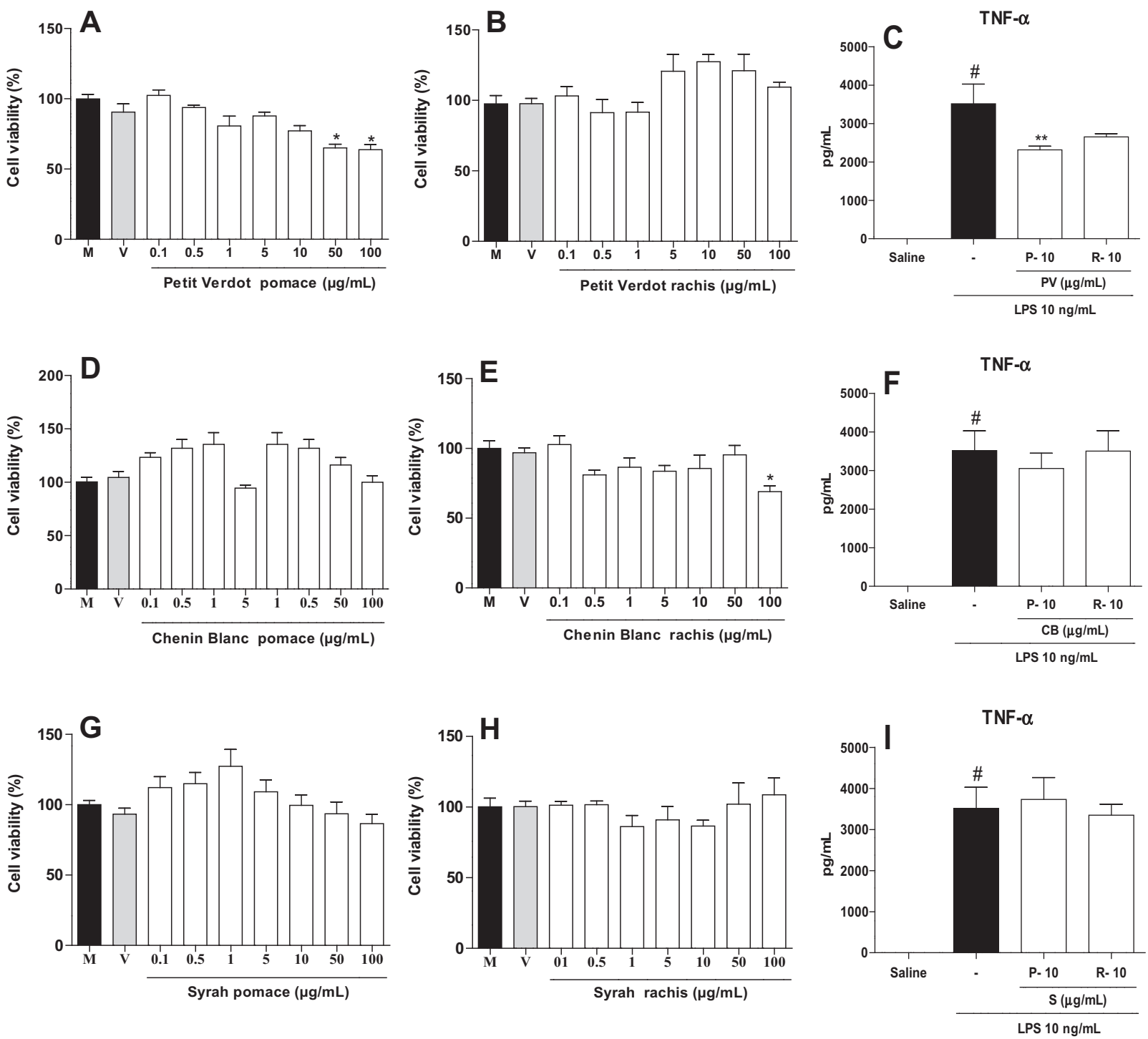

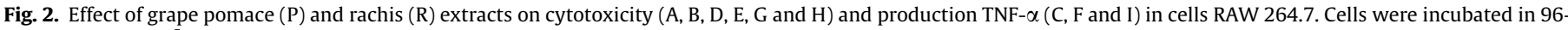

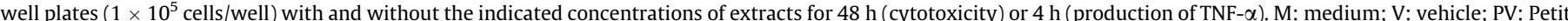

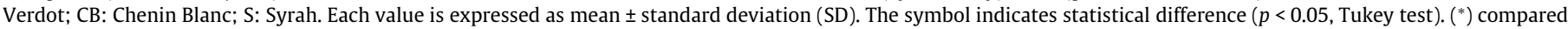
to the vehicle; (\#) compared to the saline group; $\left({ }^{* *}\right)$ compared to the LPS group. 


\section{Conclusion}

Moderate concentrations of ethanol (43\% and 57\%) combined with high temperature $\left(96^{\circ} \mathrm{C}\right)$ were the best conditions for the extraction of antioxidant compounds from Chenin Blanc, Petit Verdot, and Syrah rachis and pomace. The extracts obtained under optimized conditions exhibited good antioxidant activity and are abundant sources of bioactive molecules, such as catechin, procyanidin B1, epicatechin, and gallic acid. For winery by-product extracts from red grape varieties, the methods that use synthetic free radicals were not able to estimate the responses obtained using assays that measure the deactivation of ROS, which better represent in vivo antioxidant systems. Furthermore, winery byproduct extracts presented low toxicity against RAW 264.7 cells and Petit Verdot pomace suppressed TNF- $\alpha$ release in vitro. Based on these findings, winery by-products from the Brazilian semi-arid region can be explored as sources of natural antioxidant compounds with great potential for application in the food and pharmaceutical industries.

\section{Conflicts of interest}

The authors declare no conflict of interest.

\section{Acknowledgment}

The authors would like to thank the State of São Paulo Research Foundation (FAPESP, Grants \# 2008/55492-7 and 2011/12640-9) for the financial support.

\section{References}

Abreu, P., Matthew, S., González, T. Costa, D., Segundo, M. A., \& Fernandes, E. (2006). Anti-inflammatory and antioxidant activity of a medicinal tincture from Pedilanthus tithymaloides. Life Sciences, 78, 1578-1585. http://dx.doi.org/ 10.1016/j.Ifs.2005.07.037

Al-Duais, M., Müller, L., Böhm, V., \& Jetschke, G. (2009). Antioxidant capacity and total phenolics of Cyphostemma digitatum before and after processing: Use of different assays. European Food Research and Technology, 228, 813-821. http:/ dx.doi.org/10.1007/s00217-008-0994-8.

Alves, C. Q., David, J. M., David, J. P., Bahia, M. V., \& Aguiar, R. M. (2010). Métodos para determinação de atividade antioxidante in vitro em substratos orgânicos. Química Nova, 33, 2202-2210. http://dx.doi.org/10.1590/S0100-40422010001000033.

Amico, V., Napoli, E. M., Renda, A., Ruberto, G., Spatafora, C., \& Tringali, C. (2004). Constituents of grape pomace from the Sicilian cultivar 'Nerello Mascalese'. Food Chemistry, 88, 599-607. http://dx.doi.org/10.1016/j.foodchem.2004.02.022.

Chisté, R C. Mercadante, A. Z Gomes, A Fernandes, E Lima, J. L. F. C \& Bragagnolo, N. (2011). In vitro scavenging capacity of annatto seed extracts against reactive oxygen and nitrogen species. Food Chemistry, 127, 419-426. http://dx.doi.org/10.1016/j.foodchem.2010.12.139.

Cohen, S. D., Tarara, J. M., Gambetta, G. A., Matthews, M. A., \& Kennedy, J. A. (2012) Impact of diurnal temperature variation on grape berry development, proanthocyanidin accumulation, and the expression of flavonoid pathway genes. Journal of Experimental Botany, 63, 2655-2665. http://dx.doi.org/10.1093 jxb/err449.

Dean, R. T., Fu, S., Stocker, R., \& Davies, M. J. (1997). Biochemistry and pathology of radical-mediated protein oxidation. Biochemical Journal, 324, 1-18.

Denny, C., Lazarini, J. G., Franchin, M., Melo, P. S., Pereira, G. E., Massarioli, A. P., et al. (2014). Bioprospection of Petit Verdot grape pomace as a source of antiinflammatory compounds. Journal of Functional Foods, 8, 292-300. http:/ dx.doi.org/10.1016/j.jff.2014.03.016.

FAO. Food and Agriculture Organization of the United Nations. (2014). FAOSTAT. Retrieved from <http://faostat3.fao.org/faostat-gateway/go/to/download/Q/QC E>. (Accessed May 22, 2014).

Gomes, A., Fernandes, E., Silva, A. M. S., Santos, C. M. M., Pinto, D. C. G. A., Cavaleiro, J. A. S., et al. (2007). 2-Styrylchromones: Novel strong scavengers of reactive oxygen and nitrogen species. Bioorganic and Medicinal Chemistry, 15 6027-6036. http://dx.doi.org/10.1016/j.bmc.2007.06.046.

Halliwell, B., Aeschbach, R., Löliger, J., \& Aruoma, O. I. (1995). The characterization of antioxidants. Food and Chemical Toxicology, 33, 601-617. http://dx.doi.org 10.1016/0278-6915(95)00024-V.

Hoffmann-Ribani, R., \& Rodriguez-Amaya, D. B. (2008). Otimização de método para determinação de flavonóis e flavonas em frutas por cromatografia líquida de alta eficiência utilizando delineamento estatístico e análise de superfície de resposta. Química Nova, 31, 1378-1384. http://dx.doi.org/10.1590/S010040422008000600020.
Ivanova-Petropulos, V., Ricci, A., Nedelkovski, D., Dimovska, V., Parpinello, G. P., \& Versari, A. (2015). Targeted analysis of bioactive phenolic compounds and antioxidant activity of Macedonian red wines. Food Chemistry, 171, 412-420. http://dx.doi.org/10.1016/j.foodchem.2014.09.014.

Karacabey, E., \& Mazza, G. (2010). Optimisation of antioxidant activity of grape cane extracts using response surface methodology. Food Chemistry, 119, 343-348. http://dx.doi.org/10.1016/j.foodchem.2009.06.029.

Katalinić, V., Možina, S. S., Skroza, D., Generalić, I., Abramovič, H., Miloš, M., et al (2010). Polyphenolic profile, antioxidant properties and antimicrobial activity of grape skin extracts of 14 Vitis vinifera varieties grown in Dalmatia (Croatia). Food Chemistry, 119, 715-723. http://dx.doi.org/10.1016/j.foodchem.2009.07.019.

Kong, K. W., Mat-Junit, S., Aminudin, N., Ismail, A., \& Abdul-Aziz, A. (2012). Antioxidant activities and polyphenolics from the shoots of Barringtoni aracemosa (L.) Spreng in a polar to apolar medium system. Food Chemistry, 134, 324-332. http://dx.doi.org/10.1016/j.foodchem.2012.02.150.

Lee, J., Durst, R. W., \& Wrolstad, R. E. (2005). Determination of total monomeric anthocyanin pigment content of fruit juices, beverages, natural colorants, and wines by the $\mathrm{pH}$ differential method: Collaborative study. Journal of AOAC International, 88, 1269-1278.

Li, Z., Pan, Q., Jin, Z., Mu, L., \& Duan, C. (2011). Comparison on phenolic compounds in Vitis vinifera cv. Cabernet Sauvignon wines from five wine-growing regions in China. Food Chemistry, 125, 77-83. http://dx.doi.org/10.1016/j.foodchem.2010. 08.039.

Makris, D. P., Boskou, G., \& Andrikopoulos, N. K. (2007). Polyphenolic content and in vitro antioxidant characteristics of wine industry and other agri-food solid waste extracts. Journal of Food Composition and Analysis, 20, 125-132. http:// dx.doi.org/10.1016/j.jfca.2006.04.010.

Martínez-Lüscher, J., Torres, N., Hilbert, G., Richard, T., Sánchez-Díaz, M., Delrot, S., et al. (2014). Ultraviolet-B radiation modifies the quantitative and qualitative profile of flavonoids and amino acids in grape berries. Phytochemistry, 102, 106-114. http://dx.doi.org/10.1016/j.phytochem.2014.03.014.

Melo, P. S., Bergamaschi, K. B., Tiveron, A. P., Massarioli, A. P., Oldoni, T. L. C., Zanus, M. C., et al. (2011). Composição fenólica e atividade antioxidante de resíduos agroindustriais. Ciência Rural, 41, 1088-1093. http://dx.doi.org/10.1590/S010384782011000600027.

Monrad, J. K., Howard, L. R., King, J. W., Srinivas, K., \& Mauromoustakos, A. (2010). Subcritical solvent extraction of anthocyanins from dried red grape pomace. Journal of Agricultural and Food Chemistry, 58, 2862-2868. http://dx.doi.org/ $10.1021 /$ jf904087n.

Monrad, J. K., Srinivas, K., Howard, L. R., \& King, J. W. (2012). Design and optimization of a semicontinuous hot-cold extraction of polyphenols from grape pomace. Journal of Agricultural and Food Chemistry, 60, 5571-5582. http:// dx.doi.org/10.1021/jf300569w.

OIV. International Organisation of Vine and Wine. (2013). Statistical report on world vitiviniculture 2013. Retrieved from http://www.oiv.int/oiv/info/enstatsro?lang= en. (Accessed May 22, 2014).

O’Toole, S. A., Sheppard, B. L., McGuinness, E. P. J., Gleeson, N. C. Yoneda, M., \& Bonnar, J. (2003). The MTS assay as an indicator of chemosensitivity/resistance in malignant gynaecological tumours. Cancer Detection and Prevention, 27, 47-54. http://dx.doi.org/10.1016/S0361-090X(02)00171-X.

Pereira, G. E. Araújo, A. J. B., Santos, J. O., Oliveira, S. V., Nascimento, R. L., Quintino, C., et al. (2011). Chemical and aromatic characteristics of Brazilian tropical wines. Acta Horticulturae, 910, 135-140.

Rockenbach, I. I., Rodrigues, E., Gonzaga, L. V., Caliari, V., Genovese, M. I., Gonçalves, A. E. S. S., et al. (2011). Phenolic compounds content and antioxidant activity in pomace from selected red grapes (Vitis vinifera L. and Vitis labrusca L.) widely produced in Brazil (2011). Food Chemistry, 127, 174-179. http://dx.doi.org/ 10.1016/j.foodchem.2010.12.137.

Rodrigues, E., Mariutti, L. R. B., \& Mercadante, A. Z. (2013). Carotenoids and phenolic compounds from Solanum sessiliflorum, an unexploited Amazonian fruit, and their scavenging capacity against reactive oxygen and nitrogen species. Journal of Agricultural and Food Chemistry, 61, 3022-3029. http://dx.doi.org/10.1021/ jf3054214.

Rubilar, M., Pinelo, M., Shene, C., Sineiro, J., \& Nuñez, M. J. (2007). Separation and HPLC-MS identification of phenolic antioxidants from agricultural residues: Almond hulls and grape pomace. Journal of Agricultural and Food Chemistry, 55, 10101-10109. http://dx.doi.org/10.1021/jf0721996.

Sánchez-Moreno, C. (2002). Review: Methods used to evaluate the free radical scavenging activity in foods and biological systems. Food Science and Technology International, 8, 121-137. http://dx.doi.org/10.1106/108201302026770.

Soubeyrand, E., Basteau, C., Hilbert, G., van Leeuwen, C., Delrot, S., \& Gomès, E. (2014). Nitrogen supply affects anthocyanin biosynthetic and regulatory genes in grapevine cv, Cabernet-Sauvignon berries. Phytochemistry, 103, 38-49. http://dx.doi.org/10.1016/j.phytochem.2014.03.024.

Tir, R. Dutta, P. C., \& Badjah-Hadj-Ahmed, A. Y. (2012). Effect of the extraction solvent polarity on the sesame seeds oil composition. European Journal of Lipid Science and Technology, 144, 1427-1438. http://dx.doi.org/10.1002/ ejlt.201200129.

Wang, P., Henning, S. M., \& Heber, D. (2010a). Limitations of MTT and MTS-based assays for measurement of antiproliferative activity of green tea polyphenols. PLoSOne, 5, e10202. http://dx.doi.org/10.1371/journal.pone.0010202.

Wang, X., Tong, H., Chen, F., \& Gangemi, J. D. (2010b). Chemical characterization and antioxidant evaluation of muscadine grape pomace extract. Food Chemistry, 123, 1156-1162. http://dx.doi.org/10.1016/j.foodchem.2010.05.080. 